\title{
La crisis universitaria en América Latina y la latinoamericanización de la revista Los Libros (1969-1976)
}

\author{
The university crisis in Latin America and the Latin Americanization of the \\ Los Libros magazine (1969-1976)
}

\author{
Adrián Celentano*
}

\begin{abstract}
Resumen: El presente artículo se concentra en los análisis sobre la problemática universitaria formulados por la revista político-cultural Los Libros. Esta publicación, fundada en 1969 y clausurada en 1976 por el gobierno militar, fue dirigida en un comienzo por Héctor Schmucler y tuvo un rol clave en la consolidación de la nueva izquierda intelectual argentina. En primer lugar, nos interesamos por los rasgos materiales que caracterizan la producción y circulación de la revista. En segundo lugar, analizamos los numerosos artículos publicados por Los Libros sobre la creciente radicalización política e ideológica de los universitarios en el período que transcurre entre el Cordobazo (1969) y el Viborazo (1971). Por último analizamos el proceso registrado en los sistemas universitarios de los diversos países latinoamericanos por la revista, que atiende con especial interés los casos peruanos, chileno y boliviano, a los que se suma la compleja cuestión universitaria en Cuba, en la primera experiencia socialista de América Latina.
\end{abstract}

Palabras clave: intelectuales; revistas político-culturales; nueva izquierda; universidad

\begin{abstract}
This article focuses on the analysis of the issues raised by the political-cultural magazine Los Libros about the university. This publication, founded in 1969 and closed in 1976 by the military government, was directed at first by Hector Schmucler and played a key role in the consolidation of the argentinian new intellectual left. Firstly, we are interested in the material features that characterize the production and circulation of the magazine. Secondly, we analyze the numerous articles published by Los Libros about the growing political and ideological radicalization of the university community in the period between the Cordobazo (1969) and Viborazo (1971). Finally we analyze the process registered in the university systems in various Latin American countries by the magazine, which studies with special interest in Peruvian, Chilean and Bolivian cases wich is added the complex university question in Cuba, the first socialist experience Latin America.
\end{abstract}

Key words: intellectuals; political-cultural magazines; new left; Universit

Recibido: 29 mayo 2016

Aceptado: 4 agosto 2016

\footnotetext{
* Argentino. Profesor de Historia. Integrante del proyecto de investigación "Aportes para repensar la trayectoria de la "nueva izquierda" (1955-1976): estrategias, rupturas y reagrupamientos", María Cristina Tortti (directora), Mauricio Chama y Adrián Celentano (codirectores). Investigador del Instituto de Investigaciones de Humanidades y Ciencias Sociales de la Facultad de Humanidades y Ciencias de la Educación de la Universidad Nacional de La Plata (FaHCE-UNLP). adriancelentano@gmail.com. Agradezco a Natalia Bustelo los comentarios y la revisión del presente trabajo.
} 


\section{Presentación}

A fines de los años sesenta, la nueva izquierda intelectual erige a las revistas políticoculturales y la crítica de libros en instrumentos privilegiados tanto para su crítica cultural como para la disputa por las vías de la revolución en las sociedades latinoamericanas. ${ }^{1}$ En los debates cobra excepcional importancia la transformación de la universidad, pues las casas de estudios eran el espacio en el que intervenían muchos intelectuales y el centro de agitación del movimiento estudiantil. Aparecida entre 1969 y 1976, la revista argentina Los Libros fue una tribuna clave en la disputa por las vías de la revolución y sobre todo por la transformación universitaria en medio de lo que se consideró como la "crisis" de la universidad argentina y latinoamericana.

Respecto de la importancia asignada a la universidad, Carlos Altamirano, uno de los directores de Los Libros, subraya en la introducción de la reciente edición facsimilar que el número dedicado a la universidad se agotó rápidamente y que en él

Beatriz [Sarlo] había escrito un artículo sobre los programas de literatura argentina, que sirvió para que los estudiantes de Filosofía y Letras impugnaran, discutieran, se involucraran. A diferencia de [la revista] Crisis, Los Libros producía artículos o trabajos o dossiers que servían para el debate universitario. ${ }^{2}$

Otro testimonio sobre ese debate universitario lo ofrece Sarlo en su reciente libro autobiográfico. Allí introduce el concepto de "salto de programa" para destacar que lo imprevisto fue un elemento central en sus viajes juveniles por Bolivia y Perú y evitar cualquier mirada nostálgica sobre esa experiencia. Asimismo, toma distancia de lo que en el presente identifica como unas juveniles ilusiones "utópicas" y un "optimismo epistemológico" en los que habrían quedado atrapados sus análisis sobre el papel de los sectores populares en la lucha política. Aunque no se detiene en la problemática universitaria de aquellos países, sí enfatiza la condición estudiantil de su viaje y precisa sobre el sesgo latinoamericanista de su mirada que "buscábamos un continente en curso de transformación: había que viajar por América Latina porque el desplazamiento nos llevaría hacia formas semiocultas o más o menos visibles del futuro". 3

En este artículo nos interesa reconstruir las argumentaciones y los materiales ideológicos que Los Libros puso en circulación para el debate sobre la problemática universitaria; además, buscamos estudiar la incidencia específica de ese debate en el proceso de latinoamericanización de la revista. Respecto de la específica intervención del colectivo editor de Los Libros en el nutrido panorama de las revistas de la nueva izquierda, adelantemos que en el período que transcurre entre el Cordobazo (1969) y el Viborazo

\footnotetext{
${ }^{1}$ Seguimos aquí las orientaciones metodológicas formuladas en Beatriz Sarlo "Intelectuales y revistas. Razones de una práctica", Amèrica. Cahiers du CRICCAL, IV-V, 1993, pp. 9-16 y en Jacqueline PluetDespatin, “Une contribution à l'histoire des intellectuels: les revues. Les Cahiers de L' IHTP”, 20, 1992, pp. 125-136, (traducción inédita al español de Horacio Tarcus).

2 Elena Somoza, y Natalia Vinelli, "Introducción a Los Libros", Los Libros. Edición facsimilar, Buenos Aires, Biblioteca Nacional, 2011, pp. 9-19.

${ }^{3}$ Beatriz Sarlo, Viajes. De la Amazonía a las Malvinas, Buenos Aires, Seix Barral, 2014, 32.
} 
(1971) una de las líneas distintivas que desplegó fue la información y reflexión sobre la creciente radicalización política e ideológica de los universitarios. Sus números estudiaron los cuestionamientos a los presupuestos ideológicos de la modernización desarrollista universitaria, así como las formas organizativas y políticas del movimiento estudiantil y docente de entonces. Pero además Los Libros se preocupó por destacar los similares procesos que atravesaban los sistemas universitarios de los países latinoamericanos y se interesó especialmente en los casos peruano, chileno y boliviano, a los que sumó la compleja cuestión universitaria en la Cuba socialista.

\section{La revista en su campo}

Dirigidas en un comienzo por Héctor Schmucler y luego por un comité editor formado por Carlos Altamirano, Beatriz Sarlo y Ricardo Piglia, las treinta páginas bimestrales de Los Libros desempeñaron un papel clave en la consolidación de la nueva izquierda argentina. ${ }^{4}$ El primer editorial define la actividad de Los Libros como "crítica de la ideología". Ese será el marco desde el que promueva la crítica sistemática de las novedades bibliográficas especialmente, la renovación de las lecturas marxistas según la matriz estructuralista- ${ }^{5}$ se ocupe de los problemas de la crítica literaria que emergían por esos años y atienda a la agenda de problemas señalados por la izquierda nacional. ${ }^{6}$

Durante su primer año, Los Libros llevó por subtítulo "un mes de publicaciones en Argentina y en el mundo" e, inspirada en la revista francesa Le Quinzaine Magazine, se compuso exclusivamente de reseñas. Éstas se ocuparon de las nuevas publicaciones en historia, filosofía, economía política y sociología, pero también de libros relativos a la renovación de la crítica literaria, el psicoanálisis y las ciencias de la educación. La relación entre la historia de los movimientos obreros y estudiantiles, la caracterización del desarrollo capitalista y del imperialismo, y las formulaciones ideológicas que las acompañan fueron preocupaciones constantes de la revista, al punto de configurar lo que Panesi llamó un “discurso de la dependencia". Pero recién en 1970 esas cuestiones fueron abordadas no sólo desde las reseñas, sino también desde informes, documentos, balances y artículos. Ese año la revista también latinoamericanizó el subtítulo de su nombre: "un mes de publicaciones en América Latina"; mientras en septiembre de 1971 comienza una nueva etapa con el subtítulo "para una crítica política de la cultura"; en 1975, cuando la revista ha perdido buena parte de su carácter innovador, el subtítulo fue simplificado: "una política en la cultura".

Respecto de la composición de la dirección de Los Libros, ésta se transformó a fines de 1972 cuando Schmucler, ligado al grupo gramsciano Pasado y Presente, fue desplazado

\footnotetext{
${ }^{4}$ José Luis De Diego, ¿Quién de nosotros escribirá el Facundo?, La Plata, Al Margen, 2003.

${ }^{5}$ Horacio Tarcus, "El corpus marxista", Noé Jitrik y Susana Cella (eds.), Historia crítica de la literatura argentina, vol. 10, Buenos Aires, Emecé, 1999, pp. 465-500.

${ }^{6}$ Varios de los jóvenes intelectuales que en un comienzo colaboran en Los Libros ya pertenecían a diversos agrupamientos culturales: José Aricó, Juan Carlos Torre, Juan Carlos Portantiero y Oscar del Barco provienen del grupo editor de la revista cordobesa Pasado y Presente (1963-1965); Aníbal Ford, Ernesto Laclau, Eduardo Menéndez, Jorge B. Rivera y Eduardo Romano integran la franja intelectual de la izquierda nacional. José Panesi, Críticas, Buenos Aires, Norma, 2000, pp.17-48, y José Luis De Diego, ¿Quién de nosotros escribirá el Facundo?, La Plata, Al Margen, 2003.
} 
por tres intelectuales alineados con agrupaciones maoístas: Altamirano, Sarlo (ambos vinculados al Partido Comunista Revolucionario, PCR) y Piglia (cercano a Vanguardia Comunista). Con ese cambio la publicación se ligó a dos organizaciones de la nueva izquierda argentina que tenían una significativa presencia tanto en el movimiento estudiantil como en la formación del clasismo obrero, específicamente en la rebelde ciudad de Córdoba. ${ }^{7}$

Los Libros se dirigió a un lector universitario, no sólo por los títulos que reseñó sino también por los libros que publicitó y el estilo de las publicidades. A los numerosos anuncios de imprentas, papeleras y distribuidoras, como Librecol y DER, se sumaron editoriales centrales de la nueva izquierda argentina, como Jorge Álvarez, Tiempo Contemporáneo y Galerna -la editorial que además financió Los Libros- y anuncios de grandes editoriales, como Sudamericana, Monte Avila y Amorrurtu. ${ }^{8}$ Con el correr de los números se agregaron importantes anuncios de las editoriales universitarias de Chile, Venezuela y México, además de corresponsalías en varios países. ${ }^{9}$ Sin duda, los lectores argentinos y latinoamericanos de Los Libros habían pasado por la universidad o estudiaban en ella. Tanto ese lectorado como el equipo colaborador estuvo compuesto por mujeres universitarias. Y si bien Los Libros no destinó un espacio de reflexión a la problemática de las mujeres, éstas participaron junto a los varones -cuyas firmas fueron mayoritarias-, como corresponsales, críticas literarias y redactoras de artículos políticos, sociológicos y psicoanalíticos.

A fines de los sesenta se abre un novedoso abanico de tendencias de la nueva izquierda intelectual, en el que se destaca Los Libros y que incluye revistas como Nuevos Aires (1970-1973), Cristianismo y Revolución (1966-1971), Envido (1970-1973), Antropología 3er Mundo (1968-1973), Pasado y Presente (1963-1965 y 1973), Ciencia Nueva (1970-1973), además de los Cuadernos de Pasado y Presente (1968-1982) y las ediciones de La Rosa Blindada. ${ }^{10}$ Varias de estas publicaciones analizaron lo que se entendía como la crisis de la universidad.

Esas tendencias intelectuales compartieron ciertos rasgos: en primer lugar, promovieron una ruptura con las estructuras de los partidos de la izquierda tradicional (el

\footnotetext{
${ }^{7}$ James Brennan, El Cordobazo, Buenos Aires, Sudamericana, 1996.

${ }^{8}$ José Luis De Diego, La otra cara de Jano. Una mirada crítica sobre el libro y la edición, Buenos Aires, Amperstand, 2015.

${ }^{9}$ Los corresponsales consignados por la revista son: Alberto Lihn, Santiago Funes y Mabel Piccini en Chile, Eligio Calderón Rodríguez, en México, Adriano González León y Vilma Vargas en Venezuela, Adolfo Ferrero en Paraguay, Jorge Ruffinelli en Uruguay y Silvia Rudni en Francia.

${ }^{10} \mathrm{Sin}$ agotar las referencias, otros estudios sobre revistas de la nueva izquierda se encuentran en Ricardo Rodríguez Mazzola y Jimena Montaña, "Dossier: 50 años de Pasado y Presente. Historia, perspectiva y legados", en Prismas. Revista de historia intelectual, 18, 2014; María Cristina Tortti, CHE. Una revista de la nueva izquierda 1960-1961, Buenos Aires, CeDInCI, 2013; Ana Belén Trucco, "Dimensión, una revista de cultura y crítica. Santiago del Estero 1956-1962”, Políticas de la Memoria. Anuario de investigación e información del CeDInCI, 13, 2013, pp. 124-129; María Sondereguer, La revista Crisis 1973-1976. Antología. Del intelectual comprometido al intelectual revolucionario, UnQui, Bernal, 2008; Laura Lenci, "Cristianismo y revolución: una primera mirada", Cristianismo y Revolución, edición digital, Buenos Aires, CeDInCI, 2000; Laura Lenci y Ana Barletta, "Politización de las ciencias sociales en la Argentina. Incidencia de la revista Antropología 3er. Mundo 1968-1973”, Sociohistórica. Cuadernos del CISH, 8, 2001; Néstor Kohan, La rosa blindada. Una pasión de los sesenta, La rosa blindada, Buenos Aires, 1999; Horacio Tarcus, El marxismo olvidado. Silvio Frondizi y Milcíades Peña, Buenos Aires, El cielo por asalto, 1998.
} 
Partido Comunista y el Socialista) al tiempo que reconsideraron el fenómeno peronista (especialmente, el rol de los sindicatos y la figura de Eva Perón); en segundo lugar, replantearon el paradigma desarrollista, dominante en las instituciones académicas y científicas; en tercer lugar, intervinieron activamente en los movimientos insurreccionales que dominaron la escena política argentina entre 1969 y 1971; y, en cuarto lugar, inscribieron la disputa sobre la función del intelectual universitario en el debate latinoamericano y mundial. Teniendo en cuenta estos rasgos comunes, el apartado siguiente analiza el modo en que Los Libros caracterizó la irrupción estudiantil en el ámbito local y en el internacional.

\section{La guerra de los estudiantes}

Los Libros se ocupó de la cuestión universitaria ya en su primer número, aparecido en julio de 1969. Su tapa lleva la imagen de siluetas humanas que leen y comentan libros; allí se leen los siguientes títulos en letras destacadas: "Nueva novela latinoamericana", "El enigma Sade" y "La guerra de los estudiantes". Éste remite al artículo "Los estudiantes: nueva oposición" de Juan Carlos Torre, un miembro del grupo pasadopresentista que reseña la compilación Las luchas estudiantiles en el mundo, editada por Galerna.

Para sostener esta intervención Torre se apoya en la bibliografía de editoriales izquierdistas locales como La Anarquía y los Cuadernos de Pasado y Presente. A éstos suma artículos de intelectuales de la nueva izquierda europea, como el francés André Gorz, la italiana Rossana Rossanda y el alemán Herbert Marcuse, que publican en las revistas Les Temps Modernes y Problemi di socialismo. Son ese tipo de textos los materiales con los que se busca renovar las armas de la crítica marxista: libros, revistas, folletos y nuevas editoriales.

Torre destaca la crisis que produce en el seno de los países "neocapitalistas" la insurrección estudiantil europea. Esta insurrección, que rechaza cualquier pacto reformista, tendría una radicalidad tal que conseguiría introducir en el viejo continente el desafío planteado por la revolución cubana y la resistencia vietnamita. Los movimientos estudiantiles emergerían de la crisis del sistema capitalista moderno, se rebelarían ante la irracionalidad -criticada por Marcuse- de una sociedad que, si bien es avanzada tecnológicamente, no puede absorber los recursos generados en las universidades y termina por engendrar un "nuevo proletario" marcado por el subempleo y la desocupación.

Según Torre, los universitarios europeos, formados en concepciones humanistas, se enfrentan también al orden militar imperante en la fábrica moderna y a la alienación objetiva producida por el capital, que no puede integrar a una parte de los graduados. Frente a esa rebelión, se concluye que "no estamos ante la imagen tradicional del intelectual comprometido" sino ante un estudiante que ya desde su status "lleva la marca de la opresión" y que de ella toma "súbita conciencia", como lo había formulado Rossanda. Los universitarios llevarían su intransigencia radical hasta la ruptura con partidos, sindicatos y federaciones tradicionales y moderadas. En esa intransigencia Torre descubre el límite del movimiento: sin mediaciones ni programas, es más fácil que se pierda en el democratismo y el igualitarismo, y se integre al sistema. De todos modos, la protesta estudiantil europea se ofrecería como un gran aliciente para los estudiantes latinoamericanos que han dejado 
atrás la tradición de la Reforma Universitaria y avanzan en la lucha "revolucionaria, popular y antimperialista". 11

En los diez números siguientes de la revista, los estudiantes y la universidad son abordados sólo en artículos sobre los movimientos sociales de protesta. Recién en el número 12 (octubre de 1970), Los Libros publica una nueva reseña dedicada específicamente a la cuestión juvenil y estudiantil; se trata del libro de los intelectuales belgas residentes en Chile: Armand y Michelle Mattelart que, desde un análisis estructural, cuestionan el mito de la homogeneidad de la juventud chilena y buscan mostrar que también en ésta hay lucha de clases entre los jóvenes “dominados" y los “dominantes”. El acuerdo de la revista argentina con la perspectiva propuesta por los universitarios chilenos reunidos en el Centro de Estudios de la Realidad Nacional, se pone de manifiesto en la reseña publicada por Los Libros sobre los Cuadernos de la realidad nacional, la revista orientada por Jacques Chonchol. ${ }^{12}$

El número siguiente (noviembre de 1970) refuerza la cuestión de la lucha de clases, y ello ya desde su tapa: uno de los títulos es "Juventud y lucha de clases". Allí el sociólogo Ponciano Torales se vale de la crítica marxista y el concepto de lucha de clases para desmontar los argumentos del ensayista argentino Julio Mafud, quien pretendía explicar la rebelión juvenil argentina mediante el concepto orteguiano de "lucha de generaciones". En esta crítica se explicita la cientificidad del marxismo y de las ciencias sociales que defienden los graduados universitarios de Los Libros frente al ensayismo nacionalista. También la revista Nueva Crítica, ligada al Instituto Latinoamericano de Relaciones Internacionales y al Congreso por la Libertad de la Cultura, aparece analizada por Sarlo. A tono con las denuncias promovidas por Ángel Rama desde la revista montevideana Marcha, Sarlo cuestiona a Nueva Crítica no sólo por depender de una institución que recibía financiamiento de la CIA, sino también por la evidente "ignorancia teórica y la confusión metodológica" de los artículos de esa revista que se pretende "independiente". 13

Por su parte, la cientificidad marxista de Los Libros se enfrentaba a las diatribas "anticientificistas" que planteaban Oscar Varsavsky y el conglomerado de los intelectuales del "pensamiento nacional" de Antropología 3er. Mundo y Envido, revistas que también circulaban en la universidad. El enfrentamiento más abierto con el anticientificismo lo formula el joven althusseriano Mauricio Malamud, entonces integrante de la guerrilla Fuerzas Argentinas de Liberación (FAL). Bajo el título "Ciencia y política", Malamud reseña Ciencia, política y cientificismo de Varsavsky. Según aquél, Varsavsky les propone a los intelectuales la dicotomía de "un cientificismo sin política opuesto a un politicismo sin ciencia". Frente a ello Malamud postula al marxismo como la ciencia del cambio social, ciencia materialista que resultaría más eficaz que la vaga "ciencia rebelde" reclamada por Varsavsky para resolver los problemas nacionales. ${ }^{14}$

\footnotetext{
${ }^{11}$ Juan Carlos Torre, “La nueva oposición”, en Los Libros, 1,1969, pp. 22-23.

12 "Revistas" s/f, Los Libros, 9, 1970, p. 22.

${ }^{13}$ Beatriz Sarlo, "Nueva Crítica", Los Libros, 10, 1970, p. 27.

${ }^{14}$ Mauricio Malamud, "Ciencia y política”, Los Libros, 10, 1970, pp. 30-31. En abril de 1969 Mauricio Malamud y Luis María Aguirre publicaron bajo el seudónimo de "Camilo y Gervasio Zarate" el artículo "Ciencia y violencia" en el segundo número de Teoría y Política, la revista teórica del comité central del PCR. En ese trabajo los "Zarate" fundamentaban en términos althusserianos la necesidad del paso a la lucha armada. A raíz del impulso que dieron a esa línea fueron expulsados del PCR y se fusionaron, a principios de
} 
Bajo el título "Dos revistas, y una corriente de pensamiento" y la firma de "JCP" seguramente correspondiente a Juan Carlos Portantiero-, Los Libros analiza el proyecto de las revistas peronistas Orden del Sol, dedicada a cuestiones militares, y Envido, ligada a las "Cátedras Nacionales" de la Universidad de Buenos Aires. La reseña sostiene que el ascenso del pensamiento nacional tiene como trasfondo ideológico "la quiebra de la ilusión desarrollista-cientificista que aspiró a ser proyecto para la inteligencia posperonista" y se caracteriza por carecer de análisis específicos y sistemáticos (Los Libros, 15-16, 1971: 50). La preocupación sobre el vínculo entre los estudiantes y la ascendente "sociología nacional" probablemente alentó a Portantiero a incluir un capítulo dedicado al peronismo en Studenti e revoluzzione nell'America Latina, libro publicado en Italia el mismo año en que aparecía la reseña. ${ }^{15}$

Además de defender la cientificidad marxista, la reseña de Malamud y la de Portantiero ofrecen una interesante muestra de lo que al comienzo del presente estudio mencionamos como un rasgo distintivo de la nueva izquierda intelectual: la ubicación de las revistas político-culturales como el vehículo central en las disputas ideológicas entre las corrientes de izquierda y sobre todo en el debate sobre la peronización estudiantil.

\section{De la Reforma Universitaria al Viborazo}

A fines de 1970 Los Libros comienza a difundir otros tipos de textos. En sus números iniciales, editaba reseñas de libros firmadas por intelectuales especializados, entre los que predominaban los universitarios. Luego de algunos números suma artículos y encuestas, y desde 1970 se politiza a través de la publicación de un novedoso y variado conjunto de declaraciones, manifiestos y balances de experiencias, firmados por autores colectivos. Si buena parte de estos textos reflexionan sobre el mundo universitario, algunos de ellos permiten descubrir los nexos entre la revista y las corrientes militantes estudiantiles ligadas a las organizaciones maoístas de la época.

La tapa del número de agosto de 1971 emula un famoso afiche del mayo francés: un joven lanza una piedra que hace estallar un vidrio, detrás se deja ver el interrogante "¿Por qué Córdoba?". El afiche francés presenta a una joven mujer lanzando una piedra, la tapa de la revista argentina presenta la silueta unisex de la figura militante insurreccional. Esa insurrección protagonizada por la juventud estudiantil y los obreros a la que alude Los Libros condensa el cuestionamiento político que por esos años se escuchaba de París a Río de Janeiro y de Pekín a La Plata. En el número aparece "El movimiento estudiantil de la Reforma al Cordobazo", un artículo firmado por Osvaldo Reics y Ramón Cuevas,

1970, con los grupos que hasta ese momento integraban las FAL, ver Marcelo Starcenbaum, "Ciencia y violencia: una lectura de Althusser en la nueva izquierda argentina", II Jornadas Espectros de Althusser, CABA, 2011, pp. 346-366. Destaquemos que el común denominador entre "Ciencia y violencia" (1969) y "Ciencia y política" (1970), además de la reivindicación de la especificidad del trabajo teórico marxista, reside en la centralidad adjudicada a la discusión científica para ponerla al servicio de una política revolucionaria. Sin embargo, mientras en el texto de 1969 el trabajo teórico fundamenta la política armada, en el texto de 1970 se busca un acuerdo con el grupo de Varsavsky para promover un "Centro Argentino de Estudios Sociales Científicos".

${ }^{15}$ María Cristina Tortti y Adrián Celentano, "Estudiantes, izquierda y peronismo en la Argentina: una visión desde la nueva izquierda", María Cristina Tortti (dir.), Mauricio Chama y Adrián Celentano (cods), La nueva izquierda 1955-1976. Socialismo, peronismo, revolución, Rosario, Prohistoria, 2014, pp. 211-232. 
seudónimos de dos jóvenes intelectuales alineados con el PCR: Antonio Marimón y Horacio Crespo. Al igual que en los números dedicados a Perú y Bolivia, se publican textos que realizan análisis temáticos pero en el nuevo número aparecen firmas con seudónimos. ${ }^{16}$

El artículo de Reics y Cuevas aborda acontecimientos histórico-políticos nacionales desde una posición coincidente con las "Bases para el primer congreso del FAUDI", elaboradas en septiembre de 1971 por el frente estudiantil del PCR (entonces el principal partido maoísta argentino). La nota permite reponer la línea política del Frente de Agrupaciones Universitarias de Izquierda (FAUDI), pero además, al abarcar un amplio periodo (1945-1971), explicita la clave histórica que compartían -y llevaría a la convergencia de- los intelectuales de Los Libros y la militancia estudiantil de los partidos revolucionarios. Una afinidad que también se advierte en el hecho de que, para debatir y/o ilustrar la aplicación de su línea, Teoría y Política, la revista teórica del comité central del PCR, cite artículos publicados en Los Libros.

En primer término, el artículo de Reics y Cuevas revela dos cuestiones hasta la actualidad poco revisadas. Por un lado, llama la atención que el análisis del movimiento estudiantil allí realizado le asigne tanta importancia al FAUDI, sobre todo en la Córdoba rebelde. Por otro, debe atenderse a que ese análisis haya sido publicado junto a un informe detallado, de los mismos autores, sobre los sindicatos clasistas Sitrac-Sitram, que destaca la relación de los gremios clasistas con el movimiento estudiantil. Ambos textos revelan nexos bastante estrechos entre el FAUDI, la nueva dirección obrerista y un grupo clave de la nueva izquierda intelectual como lo era el agrupado en Los Libros. Además los dos pueden ser integrados en la discusión sobre la historia del movimiento estudiantil y de la universidad que, desde 1969, se desplegaba en torno del documentado libro de Ciria y Sanguinetti, Los reformistas, publicado por Jorge Álvarez.

Los autores inician su artículo saludando el hecho de que en 1969 el movimiento estudiantil haya roto con el legado de la Reforma Universitaria. Oponen la frustración de 1966 (año de una importante derrota del movimiento estudiantil argentino) al auge de la rebelión estudiantil correntina y rosarina de mayo de 1969, detonadora en Córdoba de un "espontaneo movimiento de deliberación por cursos" que comienza a oponerse a la "Coordinadora Estudiantil de Lucha" (asociada a la CGT de los Argentinos). Aquella espontaneidad se radicalizaría en las facultades de Arquitectura, Artes y Filosofía; en junio de ese año una asamblea de nueve mil asistentes tomó distancia de las tendencias nacionales y populares y cuestionó a la Coordinadora por "burocrática". La reivindicación del movimiento en la Facultad de Arquitectura es coherente con la publicación de un nutrido informe de la revista referido a la experiencia de Taller Total de aquella facultad, cuyo Centro de Estudiantes estaba conducido por los maoístas.

Reics y Cuevas citan el fragmento del documento del FAUDI que declara que el movimiento estudiantil debe mantenerse dentro de la Federación Universitaria Argentina (FUA) "con las banderas del Sitrac y el Sitram"; asimismo, "la alianza de organismos con la clase obrera sería más real porque incluiría a todos los estudiantes representados en las organizaciones de masas, es decir a la mayoría, y no sólo a las tendencias de izquierda y sus

\footnotetext{
${ }^{16}$ Adrián Celentano, "Insurrección obrera y compromiso intelectual. Los intelectuales de Los Libros y de Cristianismo y Revolución frente al Cordobazo y el Viborazo", Archivos de historia del movimiento obrero y la izquierda, 4, 2014, pp. 55-75.
} 
activistas". ${ }^{17}$ Tanto para el FAUDI como para los autores, la vanguardia estudiantil, en su espera de que se constituya un "instrumento político del proletariado", debería ganar las direcciones de esos organismos estudiantiles y resguardarlos del espontaneismo que promoverían las organizaciones armadas (éstas buscarían desprender al movimiento estudiantil de la FUA y transformarlo en su "apoyo logístico de masas"). Según Reics y Cuevas, los objetivos clave del bloque de izquierda estudiantil son: en lo político, la convergencia con "un producto -y proyecto político- de la clase obrera"; en lo universitario, la definitiva superación del planteo eficientista; y en lo orgánico, el avance hacia la reestructuración de la Federación Universitaria de Córdoba (FUC).

Como señalamos, los argumentos de este artículo coinciden con los propuestos en las "Bases para el congreso del FAUDI". Es más el número de Los Libros constituye un mirador privilegiado del proceso de radicalización del grupo editor, al tiempo que permite iluminar los límites de la experiencia política reivindicada por el artículo. En primer lugar, en el cuestionamiento a la Reforma del '18 el artículo adjudica el carácter liberal democrático a la condición pequeño-burguesa del estudiantado; sin embargo, cuando se ocupa del crecimiento de la nueva izquierda estudiantil, no atiende al condicionamiento de clase. En segundo lugar, el balance enfatiza la ruptura con el legado reformista por su carácter moderado; sin embargo, el texto -al igual que el documento del FAUDI- legitima los instrumentos organizativos y políticos instalados por la tradición de la Reforma (la asamblea, la movilización callejera, el centro y la federación) en tanto esos instrumentos se muestran como una vía para asegurar la masividad y evitar el espontaneismo que desembocaría en una nueva derrota.

Los diversos instrumentos empleados para la acción obrero-estudiantil son reivindicados tanto por los intelectuales de Los Libros como por los activistas estudiantiles maoístas. Esos instrumentos, que de todos modos guardan importantes deudas con el "superado" legado reformista, son inscriptos en nuevas prácticas (la insurrección, la construcción del partido revolucionario y la impugnación del academicismo).

En noviembre de 1971, tres meses después de la publicación del número dedicado a Córdoba, Los Libros elige como único título "Universidad y lucha de clases". La foto de tapa muestra una universidad que no puede ser el eje del proyecto revolucionario, pues el gran aula vacía con el cartel "Presidente honorario: Che Guevara" sugiere que, bajo ese liderazgo, los estudiantes alineados con la nueva izquierda han salido de la universidad para participar de la lucha callejera. Como veremos, la imagen y el título de este nuevo número condensan la posición de la revista sobre el momento político, esto es, la importancia de la participación universitaria en la "secuencia acontecimental" que se habría abierto en mayo de 1969 y que se extendería hasta 1971. ${ }^{18}$

El artículo dedicado al análisis general de la universidad pertenece al joven intelectual argentino Carlos Altamirano, quien ya desde el título "Universidad: cultura y dependencia" marca su divergencia con la "universidad nueva" que por entonces postulaba el antropólogo brasileño Darcy Ribeiro. Acordando con el intelectual uruguayo Mario Wschbor, Altamirano denuncia los intentos de subordinar las universidades a las políticas

\footnotetext{
${ }^{17}$ Declaración del FAUDI s/f., citado en Osvaldo Reics y Ramón Cuevas, "El movimiento estudiantil de la Reforma al Cordobazo", Los Libros, 21, 1971, p. 18.

${ }^{18}$ Tomamos el concepto de "secuencia acontecimental” de Alain Badiou, Metapolítica, Prometeo, 2010.
} 
culturales de los monopolios imperialistas (el Plan Camelot y las iniciativas de Rudolph Atcon) como parte de un "sistema". Luego reseña Hacia una política cultural autónoma para América latina, un libro editado por Marcha que trascribe las ponencias de un seminario del Centro de Estudios Latinoamericanos, que dirigía Ángel Rama y animaba Ribeiro. Sobre la ponencia del último, Altamirano sostiene que su análisis debería atender a la relación de las universidades con la estructura social y las clases dominantes del capitalismo dependiente, pues no sería suficiente denunciar el "espejismo de un crecimiento controlado desde afuera, esa modernización refleja como la llama Ribeiro, y propiciar un desarrollo independiente, planeado según los intereses nacionales" (Altamirano, 1971: 6; destacado del autor). A ojos de Altamirano, la propuesta ribeiriana de una universidad que aliada al movimiento populista deviene agente de la liberación nacional no es más que una máscara ideológica "nacional o democrática" que perpetúa la dominación. Frente a ello, opta por una intervención intelectual vinculada a la lucha de clases y crítica, desde dentro de la universidad, de la cultura dominante, sobre todo de su carácter de clase.

El número de Los Libros propone un "Balance de la actividad político-pedagógica en la Facultad de Filosofía y Letras de la UBA" firmado por la agrupación docente " 29 de mayo" de esa facultad. El texto fue redactado colectivamente y tiene en común con los demás documentos de ese número la centralidad adjudicada a la movilización de los "cuerpos de delegados de base" estudiantiles. A este balance se suman otros dos más extensos sobre los conflictos y las experiencias de los Talleres Totales implementados en las universidades de Rosario, Córdoba y La Plata. ${ }^{19}$

Dos tesis recorren entonces los textos que Los Libros publica durante 1971 sobre la situación universitaria. El proceso de crisis de las universidades argentinas formaría parte indisoluble del fracaso del proyecto global de modernización desarrollista que impulsaba desde 1966 la dictadura militar del general Onganía (en su tentativa de reordenar la sociedad argentina para beneficiar a la "gran burguesía monopólica" y "el imperialismo"). La segunda tesis que ordena las definiciones de la revista afirmaría que el movimiento estudiantil $\mathrm{y}$ docente universitario era un componente fundamental del proceso insurreccional que caracterizaba la lucha de clases desatada entre 1969 y 1971 en Argentina. Según Los Libros, el movimiento estudiantil-docente debe subordinarse a la acción revolucionaria de la clase obrera, pero ello no lo debe conducir a perder la especificidad de sus tareas en la lucha ideológica, esto es, no debe disolver la práctica teórica (especialmente, la docencia y la investigación científica) en la lucha política. Asimismo, no debe subordinarse al populismo en la acción política, como lo propiciaba por entonces la revista Antropología 3er Mundo. ${ }^{20}$

\footnotetext{
${ }^{19}$ Los otros textos del número 23 (1971) de Los Libros que componen la serie son: Equipo de Pedagogía de la FAU, "Facultad de Arquitectura de Córdoba: La experiencia de Taller Total", pp. 7-10; Adrián Caballero, "Facultad de Arquitectura de Rosario: Balance de 6 meses de lucha", pp. 11-13; s/d, "Chile: la reforma universitaria en la Universidad de Concepción", pp. 14-19; revista Movement, "Entrevista. China: los guardias rojos", pp. 20-22.

${ }^{20}$ La revista Antropología 3er Mundo, dirigida por Guillermo Gutiérrez, publicó numerosos artículos sobre la cuestión universitaria. Entre ellos se destacan: Alcira Argumedo, Roberto Carri, Horacio González, y Pablo Franco, "Cátedras Nacionales / Aportes para una ciencia popular en la Argentina”, Antropología 3er Mundo, 5 y 6, 1970; y respecto de la acción estudiantil: CEP, “CEP evalúa la experiencia del cuerpo de delegados de Filosofía y Letras", en Antropología 3er Mundo, 8, 1971, pp. 6-10. Por su parte -y hasta el cierre de Los Libros en 1976- varios trabajos de Sarlo y Altamirano marcaron sus divergencias con los intelectuales
} 
Como veremos, las ideas del colectivo intelectual agrupado en Los Libros sobre la problemática universitaria, la investigación científica y la participación estudiantil y docente en la transformación social también aparecen en los números de la revista dedicados a la situación política de otros países latinoamericanos.

\section{La crisis universitaria en la latinoamericanización de Los Libros}

A partir de 1970, con la aparición de números dedicados a Perú, Bolivia, Chile, Uruguay y Cuba, se produce la latinoamericanización de la revista Los Libros. ${ }^{21}$ En su octava entrega, el subtítulo de la revista pasa a ser "Un mes de publicaciones en América Latina" y, bajo el título "Etapa", aclara su editorial:

Con este número, LOS LIBROS comienza su "latinoamericanización". Los dos últimos meses sirvieron para preparar esta nueva etapa que se insinuaba imprescindible tanto por razones de crecimiento interno como por precisas dificultades económicas. LOS LIBROS cuenta ahora con el auspicio de algunas de las más importantes editoriales mejicanas, venezolanas, chilenas y argentinas y con un eficiente sistema de distribución que abarca América Latina, Estados Unidos y España. La mayor solidez financiera y un aumento de tiraje que cubra todas las demandas facilitará además la contratación de corresponsales en todos los países latinoamericanos a fin de ofrecer una información exhaustiva sobre los libros de interés general que aparecen y la incorporación de estudios y colaboradores de América Latina. ${ }^{22}$

Si bien, como señalan De Diego y Panesi, la latinoamericanización de la revista pasó por la ampliación del mercado y por la política, nuestro registro detenido permite precisar que esa latinoamericanización se valió de una ideología latinoamericanista preexistente en la cultura de izquierdas pero sobre todo del proceso de radicalización que atravesaban la universidad y la protesta de los sectores populares a nivel regional. Aclara otro editorial:

Al mismo tiempo que reforzamos la sección bibliográfica mediante una más estricta información y que insistimos en una crítica de libros poco común en el ámbito de América Latina, procuraremos ofrecer panoramas informativos y analíticos de problemas vinculados al destino de las naciones latinoamericanas. Manera de asumir, también por ese camino, la responsabilidad ahora

peronistas a propósito de las políticas culturales y universitarias del gobierno electo en 1973, pero también respecto de las posiciones del historiador Juan José Hernández Arregui, uno de los principales intelectuales de la izquierda peronista. Entre 1972 y 1976, las críticas de Los Libros a las posiciones de la izquierda peronista aparecen expuestas de modo sistemático en los números dedicados al sistema educativo, como aparato ideológico del Estado y especialmente en los estudios sobre la formación del sindicalismo docente, ver Celentano, 2011.

${ }^{21}$ Además de esos países, el colectivo intelectual de Los Libros atendió con menor el panorama político y cultural brasileño, por un lado mediante la denuncia de la represión y las torturas que ejecutaba la dictadura militar en ese país, y por el otro a través de trabajos del dramaturgo Augusto Boal y de la crítica a intelectuales dependentistas como el antropólogo Darcy Ribeiro.

22 "Editorial" s/f, Los Libros, 8, 1970, p. 3. 
insoslayable con la transformación que los pueblos del continente parecen haber tomado en sus manos. ${ }^{23}$

La emergencia de nuevos movimientos políticos en los países latinoamericanos tendió a involucrar a los universitarios de esos países (tanto a quienes reivindicaban el modelo del "intelectual comprometido" como a los partidarios del "intelectual revolucionario") en intensos procesos de radicalización política. ${ }^{24}$ Esta radicalización afectó tanto a las instituciones universitarias como a la relación entre cultura y revolución.

Cuando se embarca en ese proyecto, Los Libros publica principalmente artículos, balances de lucha, declaraciones y documentos de diversos agrupamientos universitarios, pero también artículos de investigadores extranjeros como el sociólogo James Petras, el autor estadounidense más publicado por la revista. Además, Los Libros publica caracterizaciones del activismo radicalizado de ese país. Entre ellas se destaca el perfil de la profesora afroamericana Ángela Davis (graduada en La Sorbona y discípula de Herbert Marcuse), entonces encarcelada por su colaboración con los Panteras Negras. ${ }^{25}$

La atención dirigida por Los Libros a las nuevas coyunturas políticas en Latinoamérica y al papel de los intelectuales en ellas era compartida en esos años por varias revistas político-culturales argentinas, especialmente por la marxista Nuevos Aires y la publicación de la izquierda peronista Cristianismo y Revolución. Ambas revistas le dedicaron numerosos artículos a la situación política de Perú, Chile y Bolivia, pero sólo la primera debatió el caso cubano.

Volviendo a Los Libros, la revista se ocupa de la intervención de los profesores y estudiantes en los procesos de reforma de la educación superior emprendidos tanto en el Perú de Velazco Alvarado como en el Chile de Allende. Además, analiza la activación universitaria que integra la oposición de izquierda al general nacionalista Torres en Bolivia. Finalmente, también problematiza la relación de los universitarios cubanos con la construcción del socialismo.

La llegada al poder de los militares peruanos encabezados por el general Velazco Alvarado produjo grandes expectativas entre los intelectuales de ese país, sobre todo porque ese gobierno impulsaba las nacionalizaciones y la reforma agraria. En el número dedicado a Perú, Los Libros valora algunas iniciativas del nuevo gobierno, aunque cuestiona las limitaciones del proceso y lo caracteriza como reformista. El abanico de opiniones de los intelectuales peruanos es mapeado por la crítica literaria argentina Josefina Delgado, quien señala la falta de coherencia de la política cultural y educativa del velazquismo. ${ }^{26}$ Además, la revista argentina incluye "La universidad actual en el Perú", un

\footnotetext{
23 "Editorial" s/f, Los Libros, 15-16 (1971) p. 3.

${ }^{24}$ Claudia Gilman, Entre la pluma y el fusil, Buenos Aires, Siglo XXI, 2003.

${ }^{25}$ James Baldwin, “Carta abierta a mi amiga Ángela Davis”, Los Libros, 17, 1971, pp. 4-5. También la revista Cristianismo y Revolución le dedica numerosos artículos al movimiento negro y a Angela Davis.

${ }^{26}$ Son encuestados por Delgado: Jose Miguel Oviedo, quien, en tanto nuevo director de la Casa de la Cultura (que había fundado José María Arguedas), aborda la conversión que propuso el gobierno en un instituto estatal de difusión de la cultura popular y promoción de la Reforma Agraria; Alejandro Romano y Reynaldo Naranjo, dos premios nacionales de poesía que explican la cooperativización de los diarios Extra y Expreso; y el profesor de la Universidad Mayor de San Marcos, Carlos Germán Belli, que caracteriza a la nueva generación de poetas peruanos. Ver Josefina Delgado, "La revolución peruana a través de sus intelectuales", Los Libros, 22, 1971, pp. 13-14.
} 
largo texto firmado por el crítico literario Antonio Cornejo Polar, entonces decano de la Universidad de Arequipa. Para éste, la nueva ley universitaria peruana, aunque mejora la estructura universitaria, aún no ha logrado resolver el problema de la falta de planificación del sistema universitario, ni la dramática exclusión de miles de estudiantes, pues no se ha modificado el sistema de admisión a la educación superior.

El decano reivindica ciertos avances de la nueva política universitaria como la creación de los "Departamentos y Programas", útiles para modernizar la enseñanza, la investigación y la extensión universitaria, mientras que es riguroso crítico de las corrientes de la izquierda universitaria. A éstas les señala que, debido a sus irreconciliables enfrentamientos internos, no aportan soluciones a los verdaderos problemas de la universidad (la construcción de una cultura nacional y la destrucción de la "cultura de la dominación"). Cornejo Polar también subraya los violentos conflictos que generaba la nueva ley al reducir la tradicional participación estudiantil en el cogobierno universitario, al tiempo que confiesa que esa participación no garantiza la excelencia académica.

La posición de Cornejo Polar podría sugerir que la reforma de la universidad peruana revela tanto los límites del intento modernizador en el que aquel participa como los límites de una izquierda universitaria reducida a sus consignas y su modelo de intelectual revolucionario.

El número doble sobre Chile (Los Libros, 15-16, enero-febrero de 1971) seguramente sea el que mejor refleje el viraje de esa revista que había comenzado como una suma de reseñas desde las que se ejercía la "crítica de la ideología". Allí aparecen artículos sobre la producción literaria chilena (especialmente el innovador trabajo crítico de Ariel Dorfman), pero también informes sobre la situación de los campesinos, los obreros y los intelectuales chilenos, y una declaración de los intelectuales y escritores sobre la cultura popular. Es que, según subraya el editorial, el objetivo estaba puesto en el estudio del proceso político que había llevado al gobierno a Salvador Allende, era un intento de "ofrecer a los lectores los trozos más significativos para el interés latinoamericano". Para ello no se apela a la crítica de libros sino que el mismo director de la publicación, Héctor Schmucler, visita quince días el país, consigue entrevistas de varios militantes del campamento popular "Che Guevara" y, a través de Armand Mattelart, se vincula a los investigadores universitarios chilenos. ${ }^{27}$

Los voluminosos anuncios a página completa de la Editorial Universidad de Chile que por entonces comienza a aparecer en Los Libros materializan la colaboración de los chilenos en la revista argentina y sugiere el interés que ésta despertó entre los lectores chilenos. El interés de Los Libros por la situación chilena era compartido con otras publicaciones de la nueva izquierda. Entre ellas, tanto Cristianismo y Revolución como Nuevos Aires dedicaron varios artículos a la nueva situación en Chile y a la radicalización de la juventud y los estudiantes en ella. ${ }^{28}$

\footnotetext{
${ }^{27}$ S/f, “En este número", Los Libros, 15-16, 1971, p. 3.

${ }^{28}$ En el caso de Cristianismo y Revolución, dirigida por el intelectual católico Juan García Elorrio, ver s/f, "Nuevo fracaso del reformismo en América Latina", Cristianismo y Revolución, 25, 1970, pp. 34-42; s/f. Esta revista católica, en trance de peronización, también se ocupó del velazquismo mediante un detenido estudio firmado por el sociólogo Roberto Carri, "Revolución peruana y peruanismo", Cristianismo y Revolución, 4, 29, 1971, pp. 46-53. Por su parte, Nuevos Aires, orientada por los críticos marxistas Vicente Battista y Mario Goloboff, dedicó su tercer número al proceso "reformista" encabezado por la Unidad Popular en Chile, ver
} 
A fines de 1971, Los Libros vuelve a preocuparse por Chile. En el ya citado número 23 se publica, bajo el título "La Reforma Universitaria de la Universidad de Concepción", un largo análisis de la situación de la universidad chilena que era parte de "un trabajo más extenso preparado por alumnos y docentes" y se enmarcaba en la reforma universitaria chilena lanzada en 1968 por la administración democristiana de Eduardo Frei. El documento lleva como epígrafe la cuarta "Tesis sobre Feurbach", en la que Marx reivindica la transformación de la educación y sostiene la necesidad de educar a los educadores como una práctica revolucionaria. En una extensa argumentación el texto erige a la docencia en el eje de la labor universitaria, exige una discusión sobre la organización de la universidad y enfatiza el valor de la metodología de la enseñanza. ${ }^{29}$

Al igual que el peruano Cornejo Polar, los autores del documento chileno entienden que la universidad tiene por misión ser "un instrumento para la transformación social". Pero, a diferencia del balance sobre Perú, los chilenos no problematizan la cuestión del ingreso a la universidad, al tiempo que valoran la participación estudiantil en el cogobierno, e incluso sugieren que los estudiantes deberían acceder al 50 por ciento de la representación. Asumiendo una matriz marxista, afirma el documento que la universidad "no puede ser modernizante" en el sentido de afianzar la dominación del capital, sino que debe desarrollar la ciencia y la cultura que expresen "los intereses de las clases explotadas". $\mathrm{Si}$ la universidad promueve entre los docentes y estudiantes la adopción de una "perspectiva práctico-teórica" que ponga en contacto los conocimientos teóricos de cada carrera con la investigación de la "realidad objetiva a que se encuentran referidas", se evitaría que los estudiantes abriguen ilusiones en la participación dentro del sistema de explotación dominante en Chile. ${ }^{30}$

Hacia su final, el documento cita la frase de Sartre "si el que juzga no es juzgado, no hay verdadera libertad", para proponer como "garantía de democracia interna" una calificación de docentes y estudiantes de carácter permanente que alcance incluso a los exámenes finales. De este modo, la docencia aparecería como el eje del conjunto de las actividades universitarias, la investigación se alinearía en la lucha de clases y el cogobierno universitario operaría como garante de ese alineamiento, ya que la superioridad de las tesis marxistas sería la que proporcione la cientificidad al conjunto del documento.

s/f, "Las otras caras de La Moneda". Ese número incluye bajo el título "Chile 1970" textos de Julio Huasi, Pablo de Rokha, Gonzalo Rojas, Enrique Lihn y Fernando Alegría, ver Nuevos Aires, 3, Buenos Aires, 1971, pp. 3-27.

${ }^{29}$ Los autores alientan la renovación de la metodología de la enseñanza y ello les permite defender el uso de la clase magistral, siempre y cuando no se abuse de ella y se la combine con métodos activos que fomenten la experimentación directa, la discusión en seminario, el trabajo en equipo y la investigación individual. A la base del planteo de los chilenos se encuentra la suposición de una fuerte motivación de los estudiantes. La propuesta de una formación integral con un plan de estudios flexible (con asignaturas divididas en obligatorias, optativas y libres) apuntaría a fortalecer una iniciativa y autonomía estudiantiles que ya se registraría en el estudiantado. Agradezco los comentarios del historiador Mario Garcés referidos a la situación en la Universidad de Concepción en los primeros años setenta.

${ }^{30}$ Para fundamentar la viabilidad de esta propuesta de una "perspectiva práctico teórica" los autores brindan ejemplos que entienden válidos para las ciencias médicas, la economía y la estadística, entre otras disciplinas. Según el documento, el abordaje integral de estas ciencias se logra a través de la compatibilización de las perspectivas históricas y las conceptuales que plantea el posfacio de la segunda edición de El Capital de Marx. 
En el número dedicado a Bolivia, yuxtapone en su tapa la imagen de los guerrilleros de Teoponte sobre un mapa de ese país. Es además, el número en que Beatriz Sarlo publica dos textos: un reportaje al escritor Augusto Céspedes y un informe político. Sin embargo, en ese número la situación universitaria es tratada escuetamente por el artículo "Bolivia entre dos revoluciones" del sociólogo estadounidense James Petras. Allí se analiza el proceso histórico de la revolución boliviana entre 1952 y 1970 y en ese marco se reconstruye la historia de los estudiantes bolivianos, quienes hasta la caída del Che Guevara habrían permanecido desligados de la lucha de clases. En efecto, la conmoción ante la muerte del Che conduciría a que el ala estudiantil democristiana, líder del movimiento universitario, se radicalice en torno de la "guerrilla de Teoponte". Si bien esa experiencia fracasó en 1970, según Petras, el marxismo revolucionario continúa teniendo un peso importante entre los docentes y los estudiantes, y ello se evidencia en la formación de "universidades obreras", en la movilización callejera junto a la clase trabajadora contra los golpes de la derecha militar (cuando el campesinado permanece ligado a los pactos con los militares) y en la participación en la "Asamblea Popular", órgano de doble poder que se enfrentaba a las claudicaciones del general Torres ante la burguesía boliviana y el imperialismo.

En el estudio de la situación boliviana propuesto por Los Libros prima, al igual que en otras revistas político-culturales como Nuevos Aires y Cristianismo y Revolución, una perspectiva centrada en las guerrillas y el movimiento obrero, mientras que la cuestión universitaria y la actividad estudiantil no merecen mayor análisis. Un enfoque similar podemos encontrar en el número de Los Libros dedicado a Uruguay: el artículo de Alain Labrousse y los documentos que se ocupan de la guerrilla tupamara no analizan específicamente la dinámica del movimiento estudiantil o los conflictos en la universidad, y ello a pesar de que los estudiantes constituían "una de las principales fuentes de apoyo al movimiento Tupamaros" y que los debates internos del movimiento tupamaro sobre el foquismo impactaron en las filas universitarias y liceales de esta guerrilla, como apunta Los Libros. ${ }^{31}$ Antes de finalizar el repaso por la latinoamericanización de Los Libros, revisemos el modo en que es tratada la cuestión universitaria cubana en el número sobre ese país.

\section{Intelectuales, política y universidad en Cuba socialista}

El número de junio de 1971 es titulado "Cuba: cultura / revolución", lleva la imagen de tapa del Che Guevara y se aboca al asunto Padilla. La barra del título separa dos términos que hasta la "autocrítica" del poeta Heberto Padilla parecían indisociables en Cuba. Padilla había "confesado" públicamente -en un discurso que parodiaba los procesos de Moscú- su condición de "contrarrevolucionario" al servicio del imperialismo; ante ello los intelectuales que apoyaban a la revolución debían posicionarse. Más precisamente, Claudia

\footnotetext{
31 Alain Labrousse, "Tupamaros, de la guerrilla al partido de masas", Los Libros, 23, 1972, pp. 3-7; completan la serie: MLN (Tupamaros), "Partido o foco: un falso dilema", pp. 8-11 y "El pensamiento tupamaro", pp. 12-13. Por su parte Cristianismo y Revolución tituló la tapa de su número 15 (1969) con la leyenda "Estos son los Tupamaros" y les dedicó sendos informes en los números 27 y 28, ambos publicados en 1971. Sobre el proceso de radicalización política e intelectual en Uruguay ver Vania Markarian, El 68 uruguayo: el movimiento estudiantil entre molotovs y música beat, Bernal, UNQui, 2012.
} 
Gilman señala que la "autocrítica" de Padilla conmociona al frente intelectual latinoamericano ligado a la revolución cubana en tanto pone de manifiesto las consecuencias de la primacía de la vanguardia política sobre la vanguardia estética.

Tanto Los Libros como Nuevos Aires organizaron reuniones para discutir la posición de los intelectuales de la nueva izquierda ante el asunto Padilla. La segunda convocó a Ricardo Piglia, David Viñas, Noe Jitrik, León Rozichtner, José Vazeilles, Mauricio Meinares y Marcos Kaplan a la mesa redonda "Intelectuales y Revolución ¿conciencia crítica o conciencia culpable?” y difundió las diversas posiciones allí asumidas. ${ }^{32}$ Por su parte, Los Libros abrió su número de junio de 1971 con "Puntos de partida para una discusión", un artículo sin firma que era el resultado del debate colectivo sobre el asunto Padilla que había tenido lugar entre los colaboradores de la revista. Para éstos el "asunto Padilla" era parte fundamental del debate sobre el sentido de la revolución y del internacionalismo proletario. Allí se impugna la postura de los intelectuales europeos (entre los que se encontraban Sartre y Rossanda) que cuestionaron al gobierno cubano, pero también las posiciones de quienes, como Rodolfo Walsh, mantuvieron su adhesión apelando a consignas emotivas que impedían discutir el papel de los intelectuales en la revolución y las del escritor García Márquez, quien se valió de un pretendido "sentido común" para eludir el análisis necesario sobre la detención, liberación y autocrítica de Padilla. Además, Los Libros rechaza a los intelectuales que pretenden ser juzgados sólo por sus pares para sostener, en clave maoísta, que los problemas de la cultura son un asunto de las masas populares cubanas. Como estaría buscando la revolución cultural china, la participación de las masas en las distintas instituciones sería la encargada de cuestionar y superar la escisión entre base y dirección. Esa participación también superaría la distinción entre trabajo manual y trabajo intelectual, y con ello reconciliaría la cultura con la revolución. En ese sentido, el artículo concluye afirmando que la revolución cubana debe avanzar mediante el debate sobre el tipo de políticas culturales y educativas que permitan desarrollar el poder y ampliar la "democracia socialista".

Junto a ese debate, el número de Los Libros difundió una carta abierta de Schmucler, el poema de Cortázar "Policrítica a la hora de los chacales", la carta de los intelectuales europeos y latinoamericanos a Fidel, el discurso de Fidel ante el Primer Congreso de Educación y Cultura y "Fidel Castro: Cultura / Revolución", una selección realizada por Los Libros de fragmentos de discursos que el líder cubano había pronunciado entre 1965 y 1968. En busca del latinoamericanismo de la revista, destaquemos que la reproducción de los documentos de Fidel parece estar orientada por el hallazgo de argumentos que autoricen y refuercen los postulados a los que la revista suscribe en "Puntos de partida para una discusión".

El editorial aclara que ante la imposibilidad de conseguir la versión en español de las resoluciones del Primer Congreso de Educación y Cultura, que acababa de realizarse en Cuba, la dirección decidió reemplazarlo por una síntesis del discurso de Fidel en la clausura de ese congreso y por la mencionada selección. Los textos que elige reproducir Los Libros versan sobre la educación y la universidad en relación con la formación de la conciencia

\footnotetext{
${ }^{32}$ La discusión es publicada de modo integro en Noe Jitrik; Marcos Kaplan; Mauricio Meinares; Ricardo Piglia; León Rozichner; José Vazeilles, "Intelectuales y revolución ¿conciencia crítica o conciencia culpable?", Nuevos Aires, 6, 1972, pp. 3-81.
} 
revolucionaria de las masas. En efecto, en uno de los discursos Fidel puntualiza que dos logros de la revolución son el acceso de las masas obreras y campesinas a la educación y el papel de ésta en la formación de la conciencia revolucionaria del pueblo cubano. Leemos que para Fidel la educación es una herramienta fundamental en la lucha contra el individualismo, al que hay que combatir en tanto enfrenta a los hombres y conduce al capitalismo. En otro de los discursos seleccionados, Fidel se dirige a la generación de becarios y técnicos graduados en 1966 para definir a la institución universitaria como parte de un proceso de integración entre la cultura y el trabajo manual. El líder los convoca a que combinen el estudio con el trabajo manual y que mantengan un persistente trabajo ideológico que evite que se conviertan en "técnicos sin conciencia" y con ello en "neoburgueses en medio de una revolución".

En el siguiente discurso, Fidel asegura que el crecimiento de la productividad en la economía socialista facilitará el avance del trabajo intelectual sobre el manual y que los éxitos de la revolución permitirán que toda la población cubana acceda a la educación superior. Asimismo, la combinación del desarrollo técnico con el educativo traería la “desaparición de la universidad" entendida como institución que separa el saber de la práctica. Entonces se abriría una etapa en la que los nuevos conocimientos científicos se aplicarían en la producción urbana y rural sin la mediación de la universidad, pues las actividades educativas se desplegarían en la misma producción.

La discusión sobre el caso Padilla tiene resonancia dos números después a través de la "Respuesta a Puntos de partida para una discusión" que elaboró el intelectual pasadopresentista Oscar del Barco en polémica con la posición adoptada por el grupo editor de Los Libros. Desde un marxismo althusseriano del Barco propone una carta abierta en la que critica abiertamente el apoyo a Fidel propuesto por Los Libros, denuncia sin ambigüedades el proceso represivo imperante en la Unión Soviética y profundiza el debate sobre la relación entre las masas, los intelectuales y los partidos comunistas. Nos interesa aquí esta carta porque encontramos en ella varios argumentos que caracterizan las discusiones producidas al interior de la nueva izquierda intelectual. ${ }^{33}$

Allí se exige distinguir las diversas instancias sociales (política, ideológica, económica) y con ello la necesaria discontinuidad entre dirigentes políticos y escritores inscritos en un proceso revolucionario. Esa discontinuidad tornaría ilegítimo, por un lado, que Fidel y cualquier hombre político no deberían dictaminar sobre cómo se debe escribir un poema o cómo se debe pintar un cuadro ni deberían apoyarse en la fuerza del Estado para dictaminar qué es lo correcto en el plano artístico; y, por el otro, que Sartre y Rossanda fueran acusados de una "indignación moralizante" -como proponen Los Libros-, y más aún porque esa indignación es la que podría evitar que se mande a escritores u homosexuales a campos de trabajo o a manicomios, como ya ocurría en la Unión Soviética. Y la carta concluye con una propuesta: "En resumen: si en política las masas populares son los dirigentes políticos, en literatura las masas son los escritores, aun cuando se dé el caso de que tanto unas (las masas) como otros (los escritores) no tengan necesariamente conciencia de tal hecho". ${ }^{34}$ De este modo la propuesta de del Barco se conecta con la posición de Los

\footnotetext{
${ }_{33}^{3}$ Oscar Del Barco, "Respuesta a Puntos de partida para una discusión”, Los Libros, 22, 1971, p. 32.

${ }^{34}$ Oscar del Barco, "Respuesta a...", p. 32. Algunos argumentos de la carta de 1971 reaparecen radicalizados por del Barco en 2006 cuando otra carta suya inicia a la extensa polémica conocida como "No matarás", ver Oscar del Barco et al, No matar. Sobre la responsabilidad, Córdoba, UNC-El cíclope, 2007.
} 
Libros: las masas populares deben ocupar el centro de la experiencia comunista para que esta lo siga siendo.

En coincidencia con la "democracia socialista" que propician los "Puntos de partida" formulados por el agrupamiento intelectual de Los Libros ante el asunto Padilla -y con la preocupación por los estudiantes y las universidades en las distintas ciudades de Latinoamérica de otros números-, las palabras de Fidel subrayan una y otra vez que la universidad es central en el destino de la revolución: el desarrollo de una intensa disputa ideológica al interior del sistema educativo y de la universidad es condición necesaria para una transformación universitaria que vincule la cultura con la revolución. O bien, en los términos de los "Puntos de partida", sólo la activa participación de las masas en las escuelas y las universidades, así como en los sindicatos y las fábricas, sería capaz de desplazar las ideas y prácticas burguesas.

\section{Conclusión}

La revisión que emprendimos registra los distintos modos en que Los Libros puso en circulación un conjunto de análisis sobre la universidad elaborados al calor de la protesta juvenil y estudiantil internacional. La oposición social que se construyó en torno de esa protesta le demandó al marxismo perspectivas y análisis renovados para definir un camino revolucionario. Y la reconfiguración de Los Libros que se advierte durante 1971 parece responder a esa demanda. En los primeros números, el colectivo editorial de Los Libros promueve la discusión sobre la juventud como categoría analítica mientras que en los años posteriores reflexiona sobre el activismo estudiantil. Los artículos, informes, editoriales y otros textos tienden a señalar al activismo estudiantil como el emergente del desarrollo de la modernización capitalista, que en la lucha de clases debería, junto a los intelectuales, colocarse como una capa subordinada a la acción de la clase obrera.

Asimismo, esos textos coinciden en identificar a la universidad como una institución atravesada por la "lucha de clases", al tiempo que defienden la especificidad del trabajo intelectual dentro del proceso de la lucha de clases. Siguiendo una categoría acuñada por Portantiero en esa época, podríamos afirmar que el movimiento estudiantil aparece como una "fuerza de trabajo intelectual en proceso de formación".

Al tiempo que en la revista pierden espacio los intelectuales de la izquierda nacional, se estrecharon los lazos entre el colectivo editorial de Los Libros y los movimientos estudiantiles que privilegiaban la estrategia insurreccional. En coincidencia con los maoístas, luego del Cordobazo y el Viborazo Los Libros se definió por la insurrección y con ello tomó distancia de los grupos universitarios y editoriales que -como Cristianismo y Revolución, Antropología 3er. Mundo y Envido- optaron por las tendencias a la acción guerrillera o por la peronización.

Nuestro recorrido permite reconocer en los números latinoamericanizados de Los Libros un conjunto de críticas a la línea política adoptada por los liderazgos que encabezaron los procesos reformistas y las políticas universitarias. Estas objeciones fueron dirigidas principalmente a los militares nacionalistas y a las organizaciones de izquierda identificadas con la vía pacífica para la toma del poder. En la insoslayable opción epocal entre "reforma o revolución", la revista optó decididamente por el polo de la revolución. Una opción que Los Libros profundizó en 1973 ante el golpe de Estado en Chile, 
oportunidad en que la revista consideró inevitable el fracaso de la experiencia de tránsito pacífico al socialismo liderada por Salvador Allende y apoyada por el Partido Comunista de ese país.

Las diversas referencias e imágenes del Che difundidas por Los Libros se ofrecen como marcas materiales de la síntesis entre el proceso radicalización de los universitarios y el de latinoamericanización de la crítica ideológica. En efecto, aunque la revista no publicó artículos firmados por el Che ni contó con textos sobre él, su imagen ilustró tres de las tapas y su nombre funcionó como una autoridad política. Estas representaciones sirvieron para saludar primero a los estudiantes cordobeses insurreccionados que, tomando el ejemplo del joven revolucionario, salieron de los claustros universitarios a la lucha de clases; y luego a la joven guerrilla guevarista de Bolivia -saludo que además subrayaba la latinoamericanización de la revista y de su colectivo editor-. Además, se apeló al Che desde la tapa del número en que se discutió la relación -ya definida por Guevara- entre cultura y revolución y que a propósito del caso Padilla se analizaron los límites del modelo del intelectual revolucionario.

El modo de intervención de los intelectuales reunidos en Los Libros tendió a asociarse a dos representaciones diferentes. Por un lado, postulando cierta autonomía relativa, reivindicaban sus posiciones teóricas como un marxismo que renovaba las ciencias sociales. Por el otro, se alineaban con las posiciones políticas de las organizaciones que se postulan como representantes del proletariado. Ambas posiciones coincidían en identificar al trabajo intelectual como parte de la producción del "hombre nuevo" latinoamericano: éste se moldearía con los instrumentos teóricos que los miembros del grupo promueven en espacios significativos de la cultura universitaria, la que contendría a la institución académica y lo que la rodea. A la vez, el carácter latinoamericano de ese hombre nuevo sería el resultado de una búsqueda en las "realidades nacionales" que, como muestran los casos de Chile, Bolivia, Uruguay, Perú y Cuba, en cada abordaje las revelan complejas y cambiantes.

Para finalizar subrayemos que Los Libros logró constituirse en esa plataforma en la que circularon trasnacionalmente las posiciones de la nueva izquierda intelectual sobre la encrucijada latinoamericana. Es que, a través de las reseñas de libros, de la actividad de las editoriales universitarias e independientes, de la compilación de documentos e informes sobre el conflicto social y de los viajes de los editores, Los Libros junto a otras revistas materializaron el proceso de construcción de una cultura universitaria ligada a la nueva izquierda y con ello mostraron que las revistas culturales podían ser no sólo un objeto editorial sino también un sujeto político.

\section{Bibliografía secundaria}

Badiou, Alain (2010), Metapolítica, Buenos Aires, Prometeo.

Brennan, James (1996), El Cordobazo, Buenos Aires, Sudamericana.

Buchbinder, Pablo (2005), Historia de las universidades argentinas, Buenos Aires, Sudamericana.

---------- Califa, Juan Sebastián y Millán, Mariano (comps.) (2010), Apuntes sobre la formación del movimiento estudiantil argentino (1943-1973), Buenos Aires, Final abierto. 
Campos, Esteban, Cristianismo y Revolución. El origen de Montoneros. Violencia, política y religión en los 60, Buenos Aires, Edhasa, 2016.

Celentano, Adrián (2007), "Una lectura política de la revista Los Libros", IV Jornadas de Historia de las Izquierdas, Buenos Aires, CeDInCI.

--------- (2011), "La historia del sistema educativo argentino y el concepto de "trabajadores de la educación' en la revista Los Libros", Jornadas Interescuelas de Historia, Catamarca.

--------- (2014), "Insurrección obrera y compromiso intelectual. Los intelectuales de Los Libros y de Cristianismo y Revolución frente al Cordobazo y el Viborazo", Archivos de historia del movimiento obrero y la izquierda, 4, pp. 55- 75.

De Diego, José Luis (2003), ¿Quién de nosotros escribirá el Facundo?, La Plata, Al Margen.

------- (2015), La otra cara de Jano. Una mirada crítica sobre el libro y la edición, Buenos Aires, Amperstand, 2015.

Del Barco, Oscar (2007), No matar. Sobre la responsabilidad, Córdoba, UNC-El cíclope.

Gilman, Claudia (2003), Entre la pluma y el fusil, Buenos Aires Siglo XXI.

Janello, Karina (2013), "El boom latinoamericano y la Guerra Fría cultural. Nuevas aportaciones a la gestación de la revista Mundo Nuevo", Ipotesi, 17, pp. 115-133.

Lenci, María Laura y Barletta, Ana María (2001), "Politización de las Ciencias Sociales en la Argentina. Incidencia de la revista Antropología 3er. Mundo 1968-1973”, Sociohistórica, 8, pp. 177-199.

Panesi, José (2000), Críticas, Buenos Aires, Norma.

Portantiero, Juan Carlos (1978), Estudiantes y política en América Latina. El proceso de la reforma universitaria (1918-1938), México, FCE.

Sarlo, Beatriz (2014), Viajes. De la Amazonía a las Malvinas, Buenos Aires, Seix Barral.

------- (1993), "Intelectuales y revistas. Razones de una práctica", Amèrica. Cahiers du CRICCAL, IV-V, pp. 9-16.

Starcenbaum, Marcelo (2011), "Ciencia y violencia: una lectura de Althusser en la nueva izquierda argentina", II Jornadas Espectros de Althusser, Buenos Aires, pp. 346-366.

Markarian, Vania (2012), El 68 uruguayo: el movimiento estudiantil entre molotovs y música beat, Bernal, UNQui.

Pluet-Despatin, Jacqueline (1992), "Une contribution à l'histoire des intellectuels: les revues", Les Cahiers de L'IHTP, 20, pp. 125-136.

Sigal, Sigal (1991), Intelectuales y poder en la década del sesenta, Buenos Aires, Puntosur, 1991.

Slipak, Daniela (2015), Las revistas montoneras. Como la organización construyó su identidad a través de sus publicaciones, Buenos Aires, Siglo XXI.

Somoza, Elena y Vinelli, Natalia (2012), "Introducción a Los Libros" en Los Libros. Buenos Aires, Biblioteca Nacional.

Tarcus, Horacio (1999), "El corpus marxista”, Noé Jitrik y Susana Cella (eds.), Historia crítica de la literatura argentina, vol. 10, Buenos Aires, Emecé, pp. 465-500.

Terán, Oscar (1991), Nuestros años sesentas, Buenos Aires, Puntosur.

Tortti, María Cristina y Adrián Celentano (2014), "Estudiantes, izquierda y peronismo en la Argentina: una visión desde la nueva izquierda", María Cristina Tortti (dir), Mauricio Chama y Adrián Celentano (cods.), La nueva izquierda 1955-1976. Socialismo, peronismo, revolución, Rosario, Prohistoria, pp. 211-232.

Weinstein, Bárbara (2013), "Pensando la historia más allá de la nación: la historiografía de América Latina y la perspectiva transnacional", Aletheia, 6.

Zarowsky, Mariano (2013), Del laboratorio chileno a la comunicación-mundo: un itinerario intelectual de Armand Mattelart, Buenos Aires, Biblos.

Bibliografía primaria 
Agrupación docente 29 de Mayo, "La agrupación docente 29 de Mayo a los compañeros de Filosofía y Letras. Balance de la actividad político-pedagógica en la Facultad de Filosofía y Letras de la UBA", Los Libros, 23, 1971, pp. 3-4.

Altamirano, Carlos, "Universidad, cultura y dependencia", Los Libros, 23, 1971, pp. 5-6.

Argumedo, Alcira; Carri, Roberto; González, Horacio y Franco, Pablo "Cátedras Nacionales / Aportes para una ciencia popular en la Argentina", Antropología 3er Mundo, 5 y 6, 1970.

Baldwin, James, "Carta abierta a mi amiga Ángela Davis", Los Libros, 17, 1971, pp. 4-5.

Battista, Vicente y Goloboff, Mario, "Las otras caras de La Moneda", Nuevos Aires, 3, Buenos Aires, 1971, pp. 3-6.

Boletín del Tercer Mundo, "Santiago (Chile)", Cristianismo y Revolución, 23, 1970, p. 52

Caballero, Adrián, "Facultad de Arquitectura de Rosario. Balance de 6 meses de lucha". Los Libros, 23, 1971, pp. 11-13.

Carri, Roberto, "Revolución peruana y peruanismo", Cristianismo y Revolución, 29, 1971, pp. 4653.

Castro, Fidel, “Cultura / Revolución”, Los Libros, 20, 1971, pp. 22-27.

CEP, "CEP evalúa la experiencia del cuerpo de delegados de Filosofía y Letras", Antropología 3er Mundo, 8, 1971, pp. 6-10.

Cornejo Polar, Antonio, "La universidad actual en Perú”, Los Libros, 22,1971, pp. 21-22.

Cortazar, Julio, "Policrítica a la hora de los chacales", Los Libros, 22, 1971, pp. 9-10.

Del Barco, Oscar, "Respuesta a Puntos de partida para una discusión", Los Libros, 22, 1971, pp. 32. Delgado, Josefina, "La revolución peruana a través de sus intelectuales", Los Libros, 22, 1971, pp. 13-14.

Equipo de Pedagogía de la FAU, "Facultad de Arquitectura de Córdoba: La experiencia de Taller Total", Los Libros, 23, 1971, pp. 7-10.

Huasi, Julio; de Rokha, Pablo; Rojas, Gonzalo; Lihn, Enrique y Alegría, Fernando, "Chile 1970", Nuevos Aires, 3, 1971, pp. 7-27.

Jitrik, Noe; Kaplan, Marcos; Meinares, Mauricio; Piglia, Ricardo; Rozichner, León y Vazeilles, José, "Intelectuales y revolución ¿conciencia crítica o conciencia culpable?”, Nuevos Aires, 6, 1972, pp. 3-81.

Labrousse, Alain, “Tupamaros, de la guerrilla al partido de masas”, Los Libros, 23, 1972, pp. 3-7.

Malamud, Mauricio, "Ciencia y política”, en Los Libros, 10, 1970, pp. 30-31.

---------- y Luis María Aguirre (seuds. "Camilo y Gervasio Zarate"), "Ciencia y violencia”, Teoría y Política, 2, 1969, pp. 34-44.

Nuevos Aires, "Cuba: Revolución en la cultura”, Nuevos Aires, 6, 1972, pp. 3-12.

Nuñez, Carlos, "Estos son los Tupamaros”, Cristianismo y Revolución”, 15, 1969, pp. 32-37.

Otero, Lisandro, "Informe sobre la cultura en Cuba", Los Libros, 21, 1971, pp. 16-20.

Portantiero, Juan Carlos, "Dos revistas y una corriente de pensamiento", Los Libros, 15-16 1971, pp. 51.

Reics, Osvaldo y Cuevas, Ramón, "El movimiento estudiantil de la Reforma al Cordobazo", Los Libros, 21, 1971, pp. 17-18.

Revista Movement, "Entrevista. China: los guardias rojos", Los Libros, 23, 1971, pp. 20-22.

Sarlo, Beatriz, "Nueva Crítica", Los Libros, 10, 1970, p. 27.

s/f, "Bolivia. La vuelta del Che", Cristianismo y revolución, 25, 1970, p. 23.

s/f, "Chile: la reforma universitaria en la Universidad de Concepción", Los Libros, 23, 1971, pp. 1419.

s/f, "Editorial”, Los Libros, 8, 1970, p. 3.

s/f, "Editorial", Los Libros, 31, 1973, p. 3.

s/f, "Editorial", Los Libros, 15-16, 1971, p. 3. 
s/f, "Revistas", Los Libros, 9, 1970, p. 22.

s/f, "Nuevo fracaso del reformismo en América Latina", Cristianismo y Revolución, 25, (1970), pp. 34-42.

Schmucler, Héctor, "Carta a Libre”, Los Libros, 20, 1971, pp. 29-30.

Torre, Juan Carlos, "La nueva oposición”, Los Libros, 1, 1969, p. 22-23. 